\section{Oxfam's case on drugs}

SiR - We are pleased that Nature $\mathbf{3 0 0}$, $395 ; 1982$ ) included a review of our latest publication "Bitter Pills: Medicines and the Third World Poor' '. But we must take exception to the headline on this piece: "Uncharitable stance from Oxfam". The relief of suffering is central to the concerns of Oxfam and poor people in the Third World are suffering - some dying - for want of essential medicines. Despite the enormous potential of the multinational drug industry to help, some manufacturers are adding to the problems of the world's poor by marketing inessential and wasteful drugs instead of catering for the need for low-priced essential generics.

Your correspondent implies that Oxfam is not helping the poor by publishing this study. Reports from our field staff and project holders in very different countries have made us forcibly aware of the damaging impact on poor people of uncontrolled drug marketing pressures. As this is clearly an issue of considerable public concern we felt compelled to publicize our findings and press for constructive solutions.

Your correspondent places great stock in the fact that "about 50 drug companies are already cooperating with WHO by promising favourable prices" for drugs. In fact all that has been promised is a "preparedness to negotiate on non-commercial prices" for drugs for the public sector. Readers familiar with the vast disparities in drug prices may wonder what concretely is being offered to poor countries. The very real fear is that the quid pro quo for low prices for the public sector will be pressure to leave the far more significant private markets largely uncontrolled. In a number of developing countries sales in the private market amount to as much as 90 per cent of total drug distribution. Because of the importance of the private market and the lack of prescription controls, this sector cannot be left uncontrolled if governments are to protect the health of the mass of their people. In 1982 Bangladesh took an important step to give priority to essential drugs by banning those that are inessential. Your correspondent describes this policy as "not ... likely to encourage further cooperation". The policy may be opposed by industry, but it must be stressed that the Bangladesh government sought to put the health of its people before commercial considerations.

Your correspondent gave the impression that Oxfam's publication is dismissive of the important work in the drugs field undertaken by WHO. Whilst stressing the enormous political constraints under which WHO must operate, we call for more support from governments of the leading drug-producing nations to help implement the resolutions they have already approved - in other words, for real action on the WHO Action Programme on Drugs. Oxfam has put forward positive proposals to help the Third World poor get the medicines they require. We now await an equally positive response from industry.

Dianna Melrose Oxfam Public Affairs Unit, Oxford, UK

\section{NCI and Frederick}

SIR - The Nature article entitled "NCI 'mismanagement' causes unrest at Frederick" (20 January, p.185) contains many factual errors in both dollar amounts and mode of operation and also creates the erroneous impression that the multicontractor environment at the National Cancer Institute-Frederick Cancer Research Center (NCI-FCRC) is proving unsuccessful. We, the undersigned, take great exception to such a judgement, given only several months of experience. We all feel that operational problems are being dealt with in a positive and effective manner. One glaring deficiency in your presentation derives from the fact that four of the contractors, comprising 80 per cent of the total contractor effort, were not contacted. This highly selected sampling invalidates any claims of objective reporting.

The NCI management team here at FCRF, along with Dr Fischinger, associate director, NCI, provides readily available guidance and oversight to ensure that all issues are dealt with in an equitable manner. In fact, it was the NCI staff and not Dr Liverman, as your article mis-states, that established transition and interface meetings to ensure appropriate contractor interaction. These were under way before the contract initiation date to ensure a smooth transition.

We have great confidence in the ability and dedication of the NCI staff to the success of FCRF. We are aware that in any large-scale operation there may be disgruntled employees and occasional thorny issues. These facts of life do not in any way justify any inference of mismanagement. In fact, our signatures, given here freely, reflect the majority view of our staffs that FCRF provides a highly productive environment for cancer research while at the same time being highly responsive to the need for accountability.

\section{RAYMOND V. GILDEN \\ JAMES L. LIVERMAr' \\ THOMAS W. DAVIS \\ PAul A. Young \\ Michele M. SANSBURY}

Frederick Operations Program Resources Inc., Litton Bionetics Inc., Harlan Sprague-Dawley Inc., Information Management Services Inc. and Data Management Services Inc.

Deborah Shapley writes - With regard to misinterpretation and errors, the article's text did not mention or imply "mismanagement" at Frederick. The headline, as well as an error in James Liverman's quote, were both copyediting errors. The article did not say that the new five-contractor arrangement at Frederick "is proving unsuccessful". Everyone agrees that the proof of success will be long term: whether the science done there continues to improve, whether good scientists can be induced to come, whether good people there now will stay. James L. Liverman, who runs the Litton contract for basic research at Frederick, explained clearly to this reporter that management was doing well considering the unusual and unexpected arrangement that NCI selected for Frederick, with five contractors running five different pieces alongside the laboratories managed directly by NCI. But scientists should judge whether management is effective in this case: if the scientists can work creatively and cooperatively and feel part of the "centre of excellence", that is NCI's stated goal for Frederick. The article said that under this arrangement some scientists are finding it difficult to do their work. This may or may not be a question of "disgruntled employees and occasional thorny issues" found "in any large-scale operation", as the letter says. Four signatories of the letter manage the support services at Frederick and were not contacted on that account.

\section{Morning stars}

Sir - Your blanket statement that astrology is sheer supersitition ${ }^{1}$ is based upon the same bigoted attitudes which were held by the sixteenth century church. I too disagree with the sweeping generalizations produced for the daily media. That is not astrology. A birth chart is based upon a unique permutation of 10 planet positions $\times 12$ zodiac signs $\times 12$ "houses" calculated from birth time, birth date and place. Astrology may not be explicable in terms of accepted physical laws, but its credibility lies in the empirical evidence of professionally cast horoscopes valid for the individuals to whom they relate.

Second, the strongest influences in astrology come not from stars but from the planets and their relative angular aspects to the Earth (or Sun). Nelson ${ }^{2}$ correlated specific heliocentric planetary alignments with increased ionospheric disturbance (which in turn disrupted short-wave radio communication). His success rate was 85 per cent.

Vegan diet, talking to plants, and communion with the dead - a widening wedge? Vegans have consistently low plasma cholesterol, high serum folate and a high fibre intake ${ }^{3}$, factors which can reduce the risk of heart and degenerative diseases. One acre of arable land can produce ten times as much plant as animal protein. This would reduce our dependence on Third World grain which we feed to cattle, and reduce an inefficient food chain.

As for communicating with unseen forces - well, astronomers, chemists and nuclear physicists are doing it all the time. Who can show me an electron?

RICHARD A. BATCHELOR

Department of Geology,

University of St Andrews, UK

1. Nature 301, 184 (1983)

2. Nelson, J.H. Elect. Engn, $421-424$ (1952)

3. Ellis, F.R. \& Montegriffo, V.M.E. Am.J.clin.Nutr. 23, 249 (1970). 